\title{
IS JOB STABILITY IN THE UNITED STATES \\ FALLING? RECONCILING TRENDS IN THE \\ CURRENT POPULATION SURVEY AND \\ PANEL STUDY OF INCOME DYNAMICS
}

\author{
David A. Jaeger \\ Ann Huff Stevens
}

Working Paper 6650

http://www.nber.org/papers/w6650

\author{
NATIONAL BUREAU OF ECONOMIC RESEARCH \\ 1050 Massachusetts Avenue \\ Cambridge, MA 02138 \\ July 1998
}

The authors thank Charles Brown, Lawrence Kahn, Henry Farber, David Neumark, Daniel Polsky, seminar participants at the City University of New York Graduate Center, the Federal Reserve Bank of New York, and the Board of Governors of the Federal Reserve, as well as participants at the Cornell-Princeton Policy Conference on Layoffs, Employment Stability, and Job Changing and the Russell Sage Conference on Changes in Job Stability and Job Security for helpful comments. They also thank Bob McIntyre and Anne Polivka for insightful discussions regarding the tenure questions in the Current Population Survey. Any opinions expressed are those of the author and not those of the National Bureau of Economic Research.

(C) 1998 by David A. Jaeger and Ann Huff Stevens. All rights reserved. Short sections of text, not to exceed two paragraphs, may be quoted without explicit permission provided that full credit, including $(\mathcal{C}$ notice, is given to the source. 
Is Job Stability in the United States Falling?

Reconciling Trends in the Current Population

Survey and Panel Study of Income Dynamics

David A. Jaeger and Ann Huff Stevens

NBER Working Paper No. 6650

July 1998

JEL No. J63

\section{ABSTRACT}

Documenting trends in job stability over the past twenty-five years has become a controversial exercise. The two main sources of information on employer tenure, the Panel Study of Income Dynamics (PSID) and the Current Population Survey (CPS), have generally given different pictures of the degree of job stability in the U.S. economy. This paper examines whether the PSID and CPS yield systematically different results with respect to comparable measures of job stability. We find that there is little evidence in either data set of a trend in the share of employed individuals with one year or less of tenure. Both data sets do show an increase in the fraction of male workers aged 30 and over with tenure less than ten years beginning in the early 1990's. We find that the two data sets provide nearly identical results for the 1980's and 1990's while in the 1970 's they give results that are somewhat less comparable. We argue that this is probably the result of changes in the CPS tenure question following the 1981 survey. The effects of this change and the choice of ending year and variable definition in PSID-based studies are the most likely explanations for the disparate findings in the literature.

David A. Jaeger

Department of Economics

Hunter College and CUNY Graduate School

695 Park Avenue

New York, NY 10021-5085

David.Jaeger@hunter.cuny.edu
Ann Huff Stevns

Department of Economics

Yale University

P.O. Box 208269

New Haven, CT 06520-8269

and NBER

ahsteven@econ.yale.edu 
The degree of job stability in the U.S. economy is of substantial concern among workers and policy-makers and has important implications for a variety of economic applications. Documenting trends in job stability over the past twenty-five years has become a controversial exercise, however. Press reports continue to emphasize deteriorating job stability, while support for this assertion from empirical economic studies has been limited. One reason for continuing ambiguity in the literature concerning trends in job stability is an apparent sensitivity of empirical results to the specific data source used. While results that differ across presumably representative and widely-used data sets are always a matter of concern among empirical researchers, the enormous attention paid recently to the issues of job stability and job security makes resolution of this issue of more than methodological interest. This paper aims to resolve one area of ambiguity by examining whether the Panel Study of Income Dynamics (PSID) and the Current Population Survey (CPS) yield systematically different results with respect to comparable measures of job stability.

The suspicion that different data sets lead to different answers concerning trends in job stability arises both from a review of the growing literature on this topic, as well as from specific references and statements within that literature. Marcotte (1994) and Gottschalk and Moffitt (1994), in particular, note that the conclusions of studies based on the PSID seem to differ systematically from those using the CPS. Examination of the conclusions of other studies in this area supports the notion that a relationship exists 
between findings and the data used. Several PSID-based studies report an increase in job mobility since the 1970s, while most CPS-based work finds no overall trend.

Despite this pattern, there has yet to be an attempt to produce a directly comparable set of results between the PSID and CPS. ${ }^{1}$ It is not possible, moreover, to reconcile the inconsistencies solely with reference to existing research. The available studies utilize different measures of job stability, have different sample coverage, and focus on several different time periods, all of which make it difficult to judge whether the different conclusions are explainable by the specific details of each study. Recent work by Diebold, Neumark, and Polsky (1997) illustrates that at least one PSID study (Rose 1995) reaches different conclusions as a result of how question changes were handled in the PSID. What is not clear from the literature is whether the CPS and PSID would yield consistent results if the samples and metric used to capture job stability were defined consistently across data sets. Because panel data such as the PSID are often necessary to answer questions relating to the consequences of job instability, it is important to know whether the PSID can produce results consistent with the CPS when changes to the survey are handled appropriately.

Our results suggest that during the 1980s and 1990s, the two data sets produce measures of job stability that are quite similar. We find little evidence in either data set of a reduction in the share of workers with employer tenure of one year or less between 1983 and 1996. We find, however, an increase in the share of workers with tenure of less than ten years between 1983 and 1996, concentrated among older male workers toward the

\footnotetext{
${ }^{1}$ One recent exception to this statement comes from work by Stewart (1997). While Stewart relies on the CPS March supplements for his work, he explicitly compares his results to those of Farber (1995) and
} 
end of the period. Both data sets also suggest a divergence in levels of job stability between more and less educated individuals during the 1980s and 1990s.

Including the 1970s in our analysis produces greater differences in trends across the two data sets. In the 1970s, the incidence of low tenure in the PSID is generally smaller than in the CPS. We argue that this is probably the result of changes in the CPS question following the 1981 survey, that may have caused low tenure rates in the 1970 s to be overstated relative to those in the 1980s. Moreover, inference across the data sets prior to 1983 is difficult because the temporally consistent measure of job tenure used in the PSID is available only for the years 1976, 1977, 1981 and 1982.

\section{Existing Literature on Trends in Job Stability}

To clarify the extent to which the data source used is related to observed trends in job stability, we begin by summarizing a number of recent studies of job stability and tenure. Among studies using the tenure data from the CPS, Farber (1995) finds that there was no overall change in the distribution of job duration between 1973 and 1993 . He does, however, find consistent evidence of a reduction in job duration among less educated men, particularly those with less than a high school education. The results presented by Diebold, Neumark and Polsky (1996, 1997, hereafter DNP), who also use the CPS tenure data, are generally consistent with these findings of little or no change in job stability. DNP report a small reduction in four year job retention rates for men from 1983 through 1991 of just over 2 percentage points after controlling for the business

Marcotte(1996). His results are quite similar to those of Farber, using the CPS tenure supplement, but not 
cycle. Among subgroups, DNP report larger than average declines in retention rates in the 1980s among less-educated workers and blacks. Over the sample period more comparable to Farber's, 1973 through 1991, DNP find a small increase in the ten year job retention rate for men, although the change is essentially zero after controlling for the business cycle. $^{2}$ Stewart (1997) employs a different CPS data set to calculate job mobility rates. His findings are generally consistent with the broad findings of other CPS-based studies in that there appears to be little overall change in job mobility among men. $\mathrm{He}$ reports a slight increase in turnover among males between 1975 and 1995.

Results from several PSID-based studies present a different pattern, however. Marcotte (1996) finds reductions in one-year job retention rates for men between 1976-78 and 1985-88 of just over two percentage points. While the estimated overall change in this study is relatively modest, Marcotte reports large increases in mobility for several demographic groups. For blacks and workers less than 25 years of age the reported reduction in job retention rates are much larger, falling by nine and ten percentage points respectively. Among education groups, Marcotte reports that dropouts and those with some college (but not a college degree) have larger than average declines in retention rates.

Two other studies using the PSID have also suggested declining job stability. Rose (1995) reports that the proportion of workers with "strong employment stability," defined as having changed employers no more than once in a decade, fell both overall and

very similar to Marcotte's, based on the PSID, again suggesting differences across the data sets.

${ }^{2}$ Swinnerton and Wial $(1995,1996)$ did find a reduction in retention rates using the CPS data, but a revision of their findings in response to comments by DNP (1996) tempers their estimated change in retention rates. Remaining differences between the findings of Swinnerton and Wial and those of DNP 
for a variety of sub-groups from the 1970s to the 1980 s. $^{3}$ A similar finding of a possible increase in rates of job changing during the late 1980s is reported in Gottschalk and Moffitt (1994). While job changing is not the primary focus of their study, they do report an increase in rates of job turnover from the 1970s to the 1980s in the PSID, although they immediately note that such an increase "is in contrast to tabulations based on the January CPS." (p. 241)

Polsky (1996) also uses the PSID, but reaches substantially different conclusions, reporting no statistically significant change in rates of job turnover between 1976-81 and 1986-91. His point estimates of the change in the probability of job separation are generally 1 percentage point or less and are statistically significant and positive only for workers in service occupations. None of the education or race groups have a statistically significant change in job separation rates over time.

Polsky identifies a potentially important reason for some of the earlier findings of increased turnover in the PSID, related to changes in a frequently used survey question during the mid-1980s. ${ }^{4}$ He notes that several of the previous PSID studies of job turnover relied on a question concerning the reason for a respondent's last job change. Changes in the questionnaire skip pattern and question wording in the 1984 through 1987 surveys make the responses to this question inconsistent over time. From 1984 through 1987 the "reason for job change" question was asked of all respondents who reported that their

appear to be related to how the authors weight the CPS data to account for non-response to the tenure question.

${ }^{3}$ DNP (1997) present evidence that Rose's findings are largely driven by his use of the "reason for job change" question in the PSID, that changed in important ways during the mid-1980s. We discuss this issue below.

${ }^{4}$ Evidence on the extent of this problem is documented in DNP (1997) in their replication of the results of Rose (1995). 
current job started after January of the previous year, rather than within the past 12 months in prior years. This artificially inflates the job changing rates based on the "reason for job change" question for these four years in the 1980s. Polsky argues that the discrepancy between his work and the findings of some other PSID-based studies can be attributed to earlier work's failure to take account of the change in the "reason for job change" question.

Overall, our reading of the literature on job stability points to many discrepancies across data sets and, to a lesser extent, across studies using the same data source. We next attempt to resolve some of these discrepancies, and to understand how they have arisen, by using comparable samples, definitions of job stability, and time periods to measure trends in the PSID and CPS. Specifically, we consider whether eliminating differences in sample composition, measures of job stability, and time periods also eliminates the differences in results across data sets.

\section{Data and Sample Construction}

In both data sets we restrict our samples to include heads-of-household and their spouses, between the ages of 20 and 59, who are employed but not self-employed at the time of the survey. The restriction to household heads and spouses is driven by data limitations in the PSID; we attempt to generate a comparable CPS sample by utilizing "reference persons" and their spouses. Information on job tenure for persons other than heads and wives is not available in the PSID and for wives it is available beginning only in 
1981. ${ }^{5}$ Because samples are extremely small for those reporting their race as neither black nor white, we also restrict the male sample to blacks and whites only. ${ }^{6}$ Additional variable definition and construction information is next described for each data source.

\section{A. PSID}

The PSID is used here primarily as a series of repeated cross-sections, and workers are included in any year in which they meet the other sample requirements. Our primary analysis uses PSID data from the 1976 through 1996 surveys, capturing employer changes during calendar years 1975 through $1995 .^{7}$ We use the entire PSID sample, including the low-income sample. PSID sample weights are used throughout. Similar results are obtained if we use only the random sample portion of the PSID and do not weight.

While we include both men and women in the analysis, data limitations in the PSID cause some of our analyses to be limited to men only. Women in the PSID can be either single female heads of household, or wives in male-headed households. Data on wives' employer tenure is available beginning in 1981, but information on race and education for wives is not available in all years through 1996. Race was asked of wives only beginning in 1984, while the early release PSID data do not have complete information on wives' education for the years 1993 through 1996.

\footnotetext{
${ }^{5}$ In the PSID the male in a two-adult household is automatically considered the "head of household."

${ }^{6}$ Because race was asked of wives beginning only in 1984 in the PSID, we do not similarly restrict the female samples.

${ }^{7}$ PSID data from 1993 to 1996 are "early release" and so these results may be subject to revision upon final release of the data.
} 
The variable of primary interest in the PSID reports the time that a worker has been with his or her current employer. We use this question to construct the fraction of individuals who are in "new" jobs, or who have employer tenure below some level. Our choice of a measure of job stability is dictated largely by the desire to have as close a counterpart as possible in the CPS tenure supplement data. This means relying on a crosssectional measure, and ignoring the panel dimension of the PSID.

Our initial measure of job stability is the share of workers with employer tenure of less than 18 months. This is intended to capture the extent to which there have been changes in the proportions of individuals who are in "new" jobs. We also present results on the fraction of workers with tenure less than 10 years to capture potential changes at a higher point in the tenure distribution. As noted by DNP (1997), the ideal measure of job stability would be one that reflects the distribution of eventual job tenure, such as retention rates, or survival probabilities at various points in the tenure distribution. Our measure, the fraction of employed workers with tenure below some level, will deviate from a retention rate measure primarily because it does not separate employer-to-employer transitions from flows of workers out of unemployment or non-employment into new jobs. An increase in the fraction of workers with low tenure could come about because (1) more workers are moving into new jobs from jobs with higher levels of tenure or (2) more workers are moving into new jobs from unemployment or out of the labor force. Any increase in the fraction of individuals with low tenure stemming from the second type of worker flow would not necessarily imply a change in job stability. To maintain consistency across the data sets, however, we rely on this simple cross-sectional measure 
and report below on the sensitivity of trends to conditioning on current or prior employment.

The choice of a time frame of less than 18 months is dictated by our desire to have a conceptually comparable measure of low tenure in the PSID and CPS. In the CPS employer tenure is generally reported in years, rather than months as in the PSID. Because we use a threshold for employer tenure in the CPS of less than or equal to one year, and assume that respondents follow a simple rounding rule, we believe the less than 18 month definition in the PSID is the most comparable. In the results for tenure less than ten years, we use a cutoff of 9.5 years in the PSID, or 114 months. For the survey years 1976 through 1977 and 1981 through 1992 this information is taken directly from questions about how long the worker has been with his current employer. An important disadvantage of using the employer tenure question is that it was not asked in the 1979 and 1980 survey, and was asked only of those under the age of 45 in 1978 . While some previous work has used alternative measures to get around this gap in coverage of the employer tenure question, we prefer to use this, the most straightforward measure of employer tenure, in those years for which it is available.

Over the course of the sample period used here, there has been one potentially important change to the employer tenure question in the PSID. Prior to 1984, the survey asked respondents how long they had worked for their present employer, without distinguishing between total time with the employer and a worker's most recent spell of employment. Beginning in 1984, respondents were explicitly asked to provide the total time they had been with their employer. For workers who have multiple spells with a 
given employer, separated either by non-employment or employment with other firms, this change in question wording will prompt different answers.

Some information is available on the potential effect of this change because, starting in 1988, the PSID collected information on length of total employment and time in the most recent spell. From the 1988 PSID we have calculated median tenure and low tenure rates based on total time with employer and time in the most recent spell. Median total tenure is approximately 2 months higher than median tenure in the most recent spell. The probability of having tenure less than 18 months is approximately 2 percentage points lower when using the total time with employer measure. This comparison, however, is very sensitive to the tenure cutoff used because the total measures are far more concentrated at six and twelve month increments. ${ }^{8}$ When we calculate the probability of having less than 12 months of tenure, for example, the total time measure actually produces a slightly higher turnover rate than the measure based on time in the most recent spell. In 1996 the CPS also collected information on total tenure and tenure in the most recent spell with an employer. In these data, the fraction of workers with total tenure of one year or less is also very close to the fraction with current tenure of one year or less.

Note that all of these results provide an upper bound on the impact of this question change in the PSID. The effect will depend on both the difference between the two measures and on the earlier PSID respondents assuming that the old question referred to time in the most recent spell. It seems unlikely, therefore, that this change will produce a noticeable distortion in the trends. To the extent that this change is important, however,

\footnotetext{
${ }^{8}$ This is because the total time measure is from a question asking for a response in months, while the time in most recent spell measure comes from a question eliciting the month and year that spell started.
} 
we would expect to see a spurious decrease in the fraction with low tenure in the PSID beginning in 1984.

The difficulties in using the PSID tenure variables to measure job changes have been explored by Brown and Light (1992). They note the substantial difficulties in identifying employer changes in the PSID, and suggest and test a number of alternative schemes for partitioning the data into jobs. Their preferred method for is based on a comparison of employer tenure with time elapsed since the previous interview. If employer tenure is less than elapsed time since the previous interview they define a job change. We follow Brown and Light (1992) in relying exclusively on the employer tenure variable from 1976 forward. The difference between our measure and their recommend measure of job change is that we focus on a fixed time period prior to the survey (18 months) rather than the time since a worker's prior survey. This again is a function of our utilization of the PSID as a series of cross-sections to be compared with the CPS crosssections, rather than using the panel nature of the data and tracing out all job changes for the same individual over time.

Finally, at least one major alternative to the employer tenure question exists in the PSID and has been used by other researchers in this literature for discerning employer changes. This is the "position" tenure question, as was used by Polsky (1996). One advantage of using this question is that is was asked in every year from 1976 through 1996. The problem, of course, is that low position tenure may reflect a recent position change or promotion but no change in the employer. Polsky (and others) use additional information on the reason for the job change to find "promotions" and eliminate these from their job change counts. The detection of promotions, however, is itself a difficult 
task. The primary source for identifying promotions is the "reason for job change" question which distinguishes promotions from other types of job changes. This is likely to leave some within-employer moves identified as job changes since some of the other possible responses could also reflect within-employer movements, ${ }^{9}$ and because of missing values in this variable. To counteract this, Polsky (1996) also compares position tenure to employer tenure and eliminates job changes for workers whose employer tenure is greater than position tenure.

An additional concern with the position tenure variable for our purposes is that between 1983 and 1984 the question wording was changed from asking about how long a worker has been in his or her present position to asking when the current position started (calendar month and year). The result of this change from responses in terms of a number of months to a responses of a starting calendar month is that heaping of responses around multiples of 12 (and 6) months is much more common prior to 1984. The employer tenure question, in contrast, has always been asked in terms of the length of employment, rather than a calendar month when the employment began. We present results below that suggest this change in the position tenure question could have important effects on conclusions regarding the time trend in job changing. ${ }^{10}$

Because the exact variable used in the PSID may be crucial to reconciling differences in the literature, we first present results comparing these alternative low tenure measures in the PSID. Figure 1 illustrates trends in several alternative low tenure series.

\footnotetext{
${ }^{9}$ Other possible responses to the reason for job change question that might also be applicable to withinemployer changes (in addition to "promotion") include "wanted a change in jobs," "other or transfer," "job completed."
} 
First, the figure shows two series based on responses to the PSID question involving "position" tenure. Using the position tenure variable we constructed a series of dummy variables equal to one if (1) position tenure is less than or equal to one year and (2) the individual's reason for changing jobs was not "promotion." This series, labeled "position < 13 months" shows a downward trend over time. We also include a comparably defined series for "position < 12 months." If heaping at 12 months becomes substantially less important following the change in question wording (from months in position to calendar month position started), these two series should be closer together starting in 1984. This is precisely what is shown in Figure 1, with the less than 13 months measure showing a slight downward trend, and the less than 12 months measure showing a slight upward trend. $^{11}$

Another important comparison in Figure 1 is that between measures based on position and employer tenure. Figure 1 shows a series based on employer tenure of less than 12 months. This comparison suggests that eliminating position changes that respondents identify as promotions leaves a substantial number of position changes that do not have a corresponding employer change. We also show the main series used for our comparisons with the CPS, representing employer tenure of less than 18 months. ${ }^{12}$

\footnotetext{
${ }^{10}$ Another alternative is to use the "reason for job change" question in the PSID. In addition to the problems noted by Polsky with use of the variable, it is triggered from the response to the position tenure question and so has all of the advantages and disadvantages of that question as well.

${ }^{11}$ This potential problem is recognized by Polsky (1996) and he adjusts for heaping by using the longitudinal aspect of the PSID to identify those who round down to one year from those who round up. While this may solve some of the problem, the patterns shown in Figure 1 nonetheless suggest that turnover rates and trends in them based on this variable may be quite sensitive to how the heaping issue is handled.

${ }^{12} \mathrm{We}$ do not include a comparable position tenure series using the 18 month cutoff since it is not generally possible to identify promotions occurring more than 12 months ago.
} 
A final example of the sensitivity of low tenure rates to the particular question used comes from inspection of the early years of the PSID data in which data are available on time in the current "job" rather than with the current employer, or in the current position. For the years 1972 through 1974 we show the probability of having job tenure of less than 12 months. ${ }^{13}$ This is relevant to our analysis because, as explained below, the early years of CPS data we use refer to "job" rather than employer. While the comparison is made difficult by differences in bracketing and by the fact that the same questions were not asked in the PSID in the same years, Figure 1 suggests that the "job" based question results in significantly higher turnover rates than those based on employer tenure.

\section{B. $C P S$}

The CPS data we employ come from the tenure supplements included in the CPS in January of $1973,1978,1981,1983,1987$, and 1991. We also use the employee benefits supplements from May 1979 and April 1993, and the displaced workers supplement from February 1996, which asked about employer tenure. ${ }^{14}$ All data are weighted by the supplement weights, when available, or by the basic CPS weight when supplement weights are not available. ${ }^{15}$ In practice, however, weighting makes very little difference to the results. ${ }^{16}$

\footnotetext{
${ }^{13}$ We use less than 12 months as the cutoff for this "job"-based series because job tenure is reported only in bracketed quantities during these years.

${ }^{14}$ Information on tenure is also available in the 1983 and 1988 employee benefits supplements.

${ }^{15}$ Supplement weights are not available in 1978 and 1981.

${ }^{16} \mathrm{We}$ also performed the analyses in the paper using adjusted supplement weights that take into account non-response to the tenure questions. This also made very little difference to the results. Further details are available from the authors by request.
} 
Our measure of job stability in the CPS is based on the tenure question asked in the various supplements. In 1973, 1978, and 1981 this question asks what year individuals started working in their current job. In these years we record individuals as having tenure of one year or less if they started working in their current job in year $t$ or in year $t-1$. Because the question was asked in January, this measures the incidence low tenure within a 13 month window. Also note the emphasis on "job" rather than "employer." Individuals could potentially give their tenure in a particular position rather than their tenure with a particular employer, thus understating their tenure with their current employer, as suggested by comparison of alternative PSID series above.

In 1979 and from 1983 forward the CPS question asks about the length of time individuals worked for their current employer. The shift from calendar to elapsed time may cause the share of workers with low tenure to increase, however. For tenure longer than 1 year, the CPS measures tenure in integer years. If individuals follow a simple rounding rule, the "1-year or less" tenure variable in the CPS will include all individuals who started working for their current employer in an 18-month window. ${ }^{17}$ Given our interpretation of the questions and responses over time, the series we report based on the "new" question represents the fraction of individuals with employer tenure less than 18 months; the "old" series refers to "job" tenure less than or equal to 13 months.

Several previous authors using the CPS have noted the question changes over time and limited their analyses to the post-1981 data. Farber (1995), however, finds that the share of individuals with low tenure remains stable using both the "old" and "new" tenure questions to examine trends spanning the change in question. We think it likely, however, 
that the simultaneous shifts from "job" to "employer" tenure and from calendar to elapsed time were roughly off-setting in their impact on our measure of low employer tenure. Given this it may be difficult to distinguish changes in job stability between the 1970s and 1990s using CPS data. In the results that follow, we show a break in series based on the "old" and the "new" questions to highlight that the series may not be consistent over time.

One difference between the CPS results in this paper and those in the literature is that previous studies using the CPS tenure supplements have not limited their focus to heads-of-household and spouses. To the extent that trends for non-heads/spouses differ from those of heads and spouses, we may find results that are at odds with this literature. We have calculated low tenure probabilities for both groups in the CPS separately and find that the share of both female and male non-heads/spouses with low tenure is higher than that for heads/spouses for both sexes. ${ }^{18}$ The trends, however, are similar. Among males, it is also the case that non-heads/spouses are a relatively small fraction of the overall sample, ranging from 10 to 15 percent of men aged 20 to 59. It seems unlikely, therefore, that this sample selection issue alone would drive differences between our study and others using the CPS.

\section{Trends in Job Stability}

A. Share of Workers with One Year or Less of Tenure

\footnotetext{
${ }^{17}$ Interviewers were instructed to follow this type of rounding rule if individual answered the "new" question with a non-integer response (Bureau of Labor Statistics 1997).

18 These results are available from the authors by request.
} 
We focus first on the share of employed individuals with 1 year or less of tenure as our measure of employment stability. Figures $2 \mathrm{a}$ and $2 \mathrm{~b}$ present trends in the fraction of workers with low tenure for the period 1973 to 1996. Error bands are twice the standard error of each annual estimate. ${ }^{19}$ For men this figure evinces little systematic difference either in level or in trend between the CPS and PSID, particularly after 1983. From 1983 through 1996, we find a slight increase in both data sets in the early 1980s, a decline during the early 1990s, and an increase in the middle 1990s. The peaks and valleys are somewhat more pronounced in the PSID (particularly the decline between 1988 and 1992), but the overall pattern of the incidence of low tenure is quite consistent between the two data sets.

In the years prior to 1983, the consistency across data sets is less clear, both because of some apparent deviations in the trends and because of fewer observations available in the PSID. Recall that the break in the CPS series between the "old" and "new" questions coincides with a change in the relevant question reference from job to employer. Thus, our expectation is that the CPS observations using the "old" question may be elevated as individuals reported changes in "jobs" that could have occurred without a change in employer. Of course, the change in the time period over which tenure is reported (from 13 to 18 months) would counter this tendency. The evidence in Figure $2 \mathrm{a}$ is consistent with the hypothesis that, on balance, the "job" to "employer" change dominates, resulting in slightly elevated low tenure rates in the early years of the CPS. The major exception to this hypothesis is 1979 , where, despite using the "new" question,

\footnotetext{
${ }^{19}$ In the CPS, standard errors are estimated as $[p(1-p) / N]^{1 / 2}$, where $p$ is the share of the sample with 1 year or less of tenure and $N$ is the number of (unweighted) observations in the cell. To address sample design issues in the PSID, standard errors are estimated using balanced half-sample replication (Wolter 1985).
} 
the incidence of low tenure would appear to be substantially higher than the surrounding years in the CPS and the PSID. Unfortunately, this comparison is based on only three annual observations in each data set, and the data points are not for the same years. Thus, our main conclusion from Figure 2a is that the two overall series are very consistent from 1983 forward, but somewhat less consistent when the 1970s are considered.

Figure $2 \mathrm{~b}$ shows the fraction of all employed women with tenure less than 18 months. The fraction of women with low tenure is generally 3 to 6 percentage points lower in the PSID, but the trends are comparable. An exception to this is 1993 in which the PSID fraction is nearly identical to that produced from the CPS. Neither data set shows strong evidence of an increase in the fraction of women with low tenure during the 1980s and 1990s. The CPS shows a slight increase in this fraction in 1996, while the PSID shows a slight decline if we consider the entire period from 1981 through 1996. As was the case for men, the 1979 observation from the CPS is substantially higher than any of the surrounding years and remains somewhat of an anomaly.

We have also explored the effects of restricting this analysis to employed individuals. If individuals lose high tenure jobs and remain unemployed for extended periods or leave the labor force, the fraction of employed individuals with low tenure will not change. To investigate this we have examined trends in the fraction of the entire population with low job tenure, counting those who are not employed in the low-tenure group. In both data sets we found that the population-based trend in the probability of having one year or less of tenure was very similar to the employment-based trends discussed below. ${ }^{20}$ Using the PSID, we have also estimated the fraction of workers with

\footnotetext{
${ }^{20}$ These results are available from the authors by request.
} 
low tenure in one year who were employed in the previous year, to eliminate new entrants into employment from our calculations. This also produced a time series with virtually the same trend.

Trends in low tenure for men, by age subgroup, are presented in Figure 3a. There is evidence from the PSID of an increase in the incidence of low tenure among young men, particularly from 1976 to 1990 . For the 20-29 year old males in the PSID low tenure rates increase from an average of .32 between 1976 and 1982 to an average of .37 between 1986 and 1996. In the CPS the low tenure share is quite stable near .36, with the exception of 1979 and 1996, where it was closer to .41. Similarly, in the CPS the low tenure share for 30-39 year olds is roughly constant near .20 for the whole sample period, with perhaps a slight movement upward in 1996; a similar pattern appears in the PSID. For 40-49 year olds the incidence of low tenure in the CPS is consistently higher than in the PSID, although the series are quite close in 1993 and 1996. While we have no explanation for this difference in level, the trends are similar to the two younger age groups. For the oldest age group of men aged 50-59, both the PSID and CPS show a very slight increase in the incidence of low tenure through the early 1990s, with a subsequent decline in the mid-1990s. This decline is more pronounced in the PSID.

For women, shown in Figure 3b, there is little evidence of any significant changes in the fraction of different age groups with low tenure between 1981 and 1996. Among the youngest women there is a decline in the fraction in new jobs from 1981 through the early 1990s and then an increase in the last few years of our sample. For the older age groups, the fractions with low tenure are relatively flat over time. 
For education subgroups, results from the two data sets are quite consistent and are presented in Figures $4 \mathrm{a}$ and $4 \mathrm{~b}^{21}$ Both data sets show a divergence between less- and more-educated workers in the proportion with low tenure. We find a substantial upward trend for men with less than 12 years of education. Trends for the middle two education groups are relatively flat, although there may be some divergence between the data sets in the 1990s. In particular, the CPS figures show an increase between 1993 and 1996 in the incidence of low tenure, while the PSID figures show a decline. The trend for men with 16 or more years of education is slightly negative in both data sets. Results for women by education level are similar to those for men, and are presented in Figure 4b. Both data sets show an increase in the fraction of female high school dropouts with low tenure between 1981 and 1992. Over the same time period there is a reduction in the fraction of employed women with at least some college education who are in new jobs. ${ }^{22}$

We have also tabulated fractions of low tenure for men separately by race. Results for white men are quite stable over time and remarkably similar across data sets. The results for blacks are more variable, reflecting the small sample sizes available in both data sets. Both sources suggest an increase in the incidence of low tenure among black men from the 1980s to the 1990s. The PSID results show a marked increase in rates of low tenure among employed black men from 1988 through 1991, followed by a decline. While we do not have an explanation for the temporarily large increase in the incidence of low

\footnotetext{
${ }^{21}$ Because the education question in the CPS changed between in January 1992, we use the recoding scheme proposed by Jaeger (1997) to define consistent groups across the break in question. In particular, Jaeger shows that agreement between the old and new questions is increased if individuals who attended but did not complete their 13th year of school are included in the "13-15" group.

${ }^{22}$ Because we have been unable to recover complete information on wives education from the PSID early release data, we have examined education-based differences for women only through 1992, the last year for which final release, fully documented PSID data are available.
} 
tenure for blacks between 1988 and 1991 in the PSID, it suggests that studies ending during this peak period would be very likely to report divergent trends in the PSID and CPS. Using the longer sample period, however, we do not find such a discrepancy.

Throughout most of these subgroup results for males, we find that the incidence of low tenure in the CPS is generally greater than that in the PSID prior to 1983 while the levels are closer from 1983 forward. This supports our hypothesis that the CPS may be understating any upward trend in the data due to the change in the tenure question in the CPS. The visual evidence presented here is certainly not consistent with any systematic differences across the data sets after 1983. Similarly, the results for women offer no evidence of a change in the probability that employed women are in low tenure jobs between 1981 and 1996.

\section{B. Alternative Measures of the Tenure Distribution}

To ascertain whether the trends and comparisons we describe in job stability are unique to the low end of the tenure distribution, we next consider an alternative measure of job stability. In Figure 5 we show the fraction of workers in each year with tenure less than 10 years for different age groups. This focuses attention on higher points in the tenure distribution and, particularly for older workers, may capture more of the potential changes in the overall distribution.

We begin by describing the results for males, shown in the left panels of Figure 5. The CPS gives consistently higher estimates than the PSID of the share of male workers with employer tenure less than 10 years, particularly for men 30-39 years old. Figure 5 
also shows, however, that the trends in these measures are comparable across data sets. For workers age 39 and under, neither data set shows a sustained trend in this measure through the entire sample period. From 1983 forward, the series for workers in their thirties exhibit a shallow U-shape in both data sets. In contrast, for workers over age 40 both data sets show an increase in the fraction of workers with less than ten years of employer tenure. Unlike the results for the fraction of workers with one year or less of tenure, using this measure suggests an upward trend from the early 80s through the end of the sample that is found in both data sets. This trend is particularly strong during the 1990s, suggesting that the change in the tenure distribution is a fairly recent phenomenon.

The results for women in Figure 5 show a different pattern. Among women, the percentages with tenure less than 10 years have declined over time. This pattern is apparent in both data sets (except for the 30 to 39 year olds in the PSID) and is stronger in the PSID for the oldest women. Among women this measure of tenure less than 10 years shows no evidence consistent with a reduction in job stability.

We have also compared the full distributions of tenure in the CPS and PSID samples. To summarize these distributions over time we followed Farber (1995) and calculated interpolated quantiles of the distributions. Medians and $90^{\text {th }}$ percentiles were calculated separately by the age groups shown in Figure 5. This comparison results in much the same story as the probabilities of tenure less than ten years. ${ }^{23}$

\section{Multivariate Trend Regressions}

\footnotetext{
${ }^{23}$ Tables showing these results are available from the authors by request.
} 
To control for changes in composition within subgroups, we performed regression analysis of the incidence of low tenure using the PSID and CPS. This allows us to hold individual characteristics (age, education and race) constant and examine changes in the adjusted probabilities over time. Because the samples are more educated and slightly older by 1996 than in 1983, changes in the sample composition over time could mask changes in the fraction of workers with given characteristics with low tenure.

The estimation proceeds in two steps. In the first step we estimate a logit model on the probability of having employer tenure of less than one year or less than ten years and control for age, age squared, race, education and calendar year. ${ }^{24}$ Using the calendar year coefficients we then create year-specific probabilities. ${ }^{25}$ In the second step of the estimation these probabilities are regressed on a time trend using OLS. Because the error term in this second-stage regression is heteroskedastic, we present heteroskedasticityconsistent standard errors estimated using the jackknife. ${ }^{26}$ We estimate the model for the full sample as well as separately for each age, education, and race group; the results are presented in Table 1.

The first four columns of Table 1 show the estimated trends in the regressionadjusted probabilities of tenure of one year or less for the two data sets. We show results for both the full periods and for the 1983 through 1996 period. We focus our attention on the latter period because we view the samples as more consistent (and more comparable to one another) from 1983 through 1996. Between 1983 and 1996, for the full sample,

\footnotetext{
${ }^{24}$ We control for education by including dummy variables for the education groups shown in Figure 4 .

${ }^{25}$ In creating these probabilities the logit function is evaluated at the observed mean of the other covariates.
} 
neither data set produces a statistically significant trend in rates of tenure less than or equal to one year. Within certain subgroups, the estimated trend in the CPS is larger, although often not statistically significant. In the PSID, there are statistically significant trends only for 40-49 year olds, high school graduates and blacks. The trends for 40-49 year olds (as well as 50-59 year olds) and high school graduates are also statistically significant in the CPS. In addition, the estimated trend for black men has a large point estimate in the CPS, but has an equally large standard error.

The results for the period beginning in the 1970s are substantially different than those beginning in the 1980s. First, in the PSID, including the years 1976, 1977, 1981, and 1982 produces a statistically significant and upward trend for almost every subgroup. The pattern of a smaller increase in the CPS from the 1970s and 1980s is consistent with our hypothesis that the question changes lead to an overstatement of low tenure probabilities prior to 1983. The PSID data are more consistent over the entire period from 1976 through 1996, and provide evidence of a small increase in the fraction of male workers in new jobs from the mid-1970s to the mid-1990s. This evidence also indicates that measured trends in job tenure are sensitive to the exact period under consideration.

Columns 5 through 8 of Table 1 present results for the trend in the percentage of workers with employer tenure of less than 10 years. The trend in the fraction of men with less than 10 years of employer tenure is positive and statistically significant in almost every subgroup from 1983 to 1996 . The estimated trend is stronger in the PSID, with the magnitude of the trend effect typically equal to approximately twice the trend estimated

\footnotetext{
${ }^{26}$ MacKinnon and White (1985) show that the small-sample performance (which is certainly relevant here!) of jackknife standard errors is superior to other heteroskedasticity-consistent standard errors such as those suggested by White (1980).
} 
using the CPS. After adjusting for age, education and race, there is strong evidence from both data sets that workers are more likely to be in jobs with tenure less than ten years in the 1990s relative to the 1980s. In general the regression-adjusted probabilities provide more evidence of a decrease in job stability than did the unadjusted figures shown in the previous section. ${ }^{27}$ This is not surprising since the sample is both more educated and older at the end of the period and both of these characteristics are associated with lower probabilities of being in relatively new jobs.

\section{Discussion and Conclusion}

We conclude from these results that the PSID and CPS provide consistent pictures of job stability during the 1980s and 1990s. Overall, the fraction of workers with very low employer tenure (one year or less) changed little during this period. Less educated individuals had increasing probabilities of being in new jobs while college graduates had stable or slightly decreasing probabilities. When we consider the fraction of workers in jobs with less than ten years of tenure however, there is consistent evidence of a decrease in employer tenure over the 1980s and 1990s. This decrease was particularly strong during the 1990s when we control for the age, race, and education composition of the samples.

Differences in the trends based on measures of tenure less than or equal to one versus less than ten years suggest some ambiguity in our overall conclusion regarding job

\footnotetext{
${ }^{27}$ In addition to the evidence from the figures in previous sections, we have also estimated the trend terms shown in Table 1 without conditioning on age, education and race in the first stage. These "unadjusted" trend coefficients are consistently smaller and are often not statistically significant.
} 
stability. These measures, as noted above, are imperfect summaries of job stability, or eventual tenure distributions, but are most directly comparable across data sets. Much prior work has focused on one-year turnover probabilities that are closely related to our less than one year of tenure measure. One consistent interpretation of our results is that the late 1980s and early 1990s were a period of relatively high job separation rates, particularly for certain workers. ${ }^{28}$ Workers who lost or left jobs during this period must necessarily have elevated probabilities of having tenure less than ten years over the next decade. This suggests that the trends we find in the fraction of workers with less than ten years of tenure may be the result of high rates of job separations in the late 1980s and early 1990s, which have since declined.

When we focus on longer periods that include the 1970s, there are greater differences between the PSID and CPS. In particular, it appears that the incidence of low tenure was greater in the CPS than in the PSID before 1983. We believe this pattern of deviations is likely attributable to the change in focus from "job" to "employer" tenure in the CPS. Results from the PSID, summarized in Figure 1, suggest that this type of change can give substantially lower estimated probabilities of low tenure. The impact of this change was likely masked in the CPS, however, because the effective time period covered by "1 year or less" of tenure may have increased at the same time. An additional limitation on comparing job stability from the 1970 s to a later period is that a tenure measure consistent with subsequent years is available only for 1976 and 1977 in the PSID.

\footnotetext{
${ }^{28}$ Farber (1997) reports that job loss rates were unusually high from 1989 through 1991, particularly for workers over age 35 .
} 
We conclude by returning to the questions that motivated this work: (1) has there been a trend towards decreased job stability, and (2) does the answer to this question differ between the CPS and the PSID? In answer to the first question, we present evidence of reduced levels of job tenure for employed men between the 1980s and the 1990s. Both data sets show a statistically significant increase in the probability of workers having less than ten years of tenure. We find no continued trend in the fraction of workers with very low tenure, however, suggesting that this may not reflect a permanent downward shift in the probability of remaining with a given employer, as has been suggested in much of the popular press.

Perhaps even more central to the specific goals of this paper, our answer to the second question is no. We believe our results illustrate the comparability of trends measured from the two data sets, once consistent data series, variable definition, and time periods are utilized. Across both data sets there is a divergence in our measures of job stability between more and less educated workers, and between men and women from the 1980s to the 1990s. Both data sources also show little or no trend in the probability that a worker has one year or less of tenure and stronger trends probability that a worker has less than ten years of tenure. The timing of these changes seems to be centered in the late 1980s and early 1990s.

We find several explanations for the apparent sensitivity of previous estimates of job stability or turnover to the particular data used. The general tendency for PSID studies to find an upward trend in employment instability where none is found using CPS data may be explained by three factors: 
(1) Tenure estimates or job changing rates based on PSID data may be very sensitive to the particular variables used. Some of the increase found in the PSID, as noted by DNP (1997) results from failure to account for major changes in the questions regarding job and position changing that occurred during the 1980s. As emphasized by our Figure 1, the exact choice and definition of variables in the PSID can substantially affect the resulting trends. When we use the variable we believe to be most comparable to the CPS series, however, we find the two data sources to produce consistent estimates through the 1980s and mid 1990s.

(2) The comparison of the PSID and CPS shows some sensitivity of results to the exact time period studied. Many of the previous PSID studies have included data only through 1988, when the probability of having tenure of 1 year or less appears to have peaked in those data. This is not, however, inconsistent with the CPS findings once the later years of both surveys are included. Similarly, the trends we find over the course of the 1980s and 1990s in the PSID are also sensitive to whether we begin the period in 1981 or $1983 .^{29}$ A related point here is that individual year estimates of job tenure or job changing probabilities in the PSID are, by virtue of the sample sizes available, substantially less precise than those in the CPS.

(3) While we cannot say with certainty, we also present evidence that suggests the CPS question change prior to 1983 may have an important effect on comparisons across data sets. For comparisons starting in the 1970s, the upward trend in instability found in the PSID for some groups (young workers, for example) may reflect genuine changes

\footnotetext{
${ }^{29}$ We do not believe this is the result of different business cycle conditions in the different years. We have also estimated trends holding constant the unemployment rate and alternative business cycle controls obtained similar results.
} 
(although relatively small) in job mobility. These changes may not have been replicated in the CPS-based studies either because those studies did not include the 1970s or because the CPS question change masks this increase.

In many cases a combination of these factors contributes to the apparent differences in findings across data sets. For example, the PSID study by Marcotte (1996) is based on a relatively young sample of workers under age 45 and goes from 1976 through 1988. Our results from the PSID are quite consistent with his finding of some increase in job mobility for young men over this time period. We should also note that two other recent studies using the National Longitudinal Survey of Youth, by Monks and Pizer (1996) and Berhnhardt, Morris, Handcock, and Scott (1998), find an increase in turnover among young men from the 1970s to the 1980s. We believe that the lack of CPS-based evidence for such an increase over this time period is not necessarily informative given the potential problems with comparability of the CPS between the two decades.

Polsky (1996) is the one PSID-based study that finds virtually no increase in turnover rates, despite beginning his analysis in the 1970s. This result is likely driven his inclusion of data through 1991 (when some of the temporary increase in the late 1980s had been reversed) and because his measure of turnover is based on the position tenure question that measures a somewhat different quantity than employer tenure. As indicated in Figure 1, use of slightly different questions in the PSID can produce quite different time-series of measures involving position or employer tenure.

Our results from both data sets during the 1980s are quite consistent with the findings of DNP (1997) and a recent extension of this work by Neumark, Polsky, and 
Hansen (1998). These studies are somewhat unique among the CPS studies in that it utilizes data from the CPS prior to the 1983 question change and constructs a strategy for dealing with this change. DNP (1997) produce two main sets of estimates: one covering the period 1983 through 1991, and a second covering 1973 through 1991. DNP report small reductions in four-year retention rates for men over the first time period, with relatively larger reductions for blacks, less educated workers, younger workers and workers who begin the period with between two and nine years of tenure. Neumark, Polsky, and Hansen (1998) show that there is some evidence of a decline in job stability when the time period is extended through the first half of the 1990s.

In our full samples we find similarly find little evidence of reduced job stability during the period from 1983 to 1991 . Trends across education results presented here also show greater reductions in stability among less-educated workers. Among black men from 1983 to 1991 we also find a small increase in the fraction low-tenure in our CPS estimates, and a large increase in the PSID estimates over this period. Our results differ from DNP with respect to young workers during this time period; we find no evidence that young workers' chances of being in low-tenure jobs increased more than that for older workers in the 1980s using the PSID. While our measures of the fraction of men in jobs with less than one or ten years of tenure are not directly comparable to DNP's retention rates from different starting points in the tenure distribution, we find a qualitatively similar result with respect to different measures of "low" tenure. In particular, we find more evidence of increased instability over the 1980s in measures of the proportion with less than ten years of tenure than in measures of less than or equal to one year. This is consistent with retention rates falling not in the very early months of 
employment, but in subsequent years on the job. Finally, as we show in Figure 5, much of the increase that we do report in the fraction of workers with less than ten years of tenure occurs during the early part of the 1990s, consistent with the findings of NPH (1998).

While we view our findings as roughly consistent with DNP's from the 1980s to the 1990s, we find less agreement in the 1973 to 1991 period. Both our study and DNP's find no strong overall trend in job stability over this period. Among education sub-groups, however, we find the same trend as in the later period, of reduced stability for lesseducated workers and increased stability for more educated groups. DNP report that tenyear retention rates for college graduates over this period fell by more than those of lesseducated groups. Similarly, our results by age subgroups differ qualitatively from their study. We find larger increases in the fraction low-tenure among workers 29 and younger from 1976 through 1991, while DNP find that retention rates increased substantially among the youngest workers from 1973 to 1991. Of course, our PSID results used as the basis for comparison in the 1970s involve only two years in the late 1970s. We are thus not surprised that results focused on the 1980s forward are far more consistent with these previous findings.

Using what we view as the cleanest and most consistent variable to measure tenure in the PSID produces estimates that differ very little from comparable CPS estimates from 1983 to 1996 . This is an important finding for researchers interested in utilizing either the panel nature of the PSID or the much larger samples sizes available in the CPS to study issues related to job tenure or job stability. While previous work has focused on the difficulties with the PSID tenure variable, and several recent studies have produced results seemingly at odds with CPS-based studies, we are able to produce consistent results 
across the two data sets once comparable time-frames, variable definitions, and samples are used. 


\section{REFERENCES}

Bernhardt, Annette, Martina Morris, Mark Handcock, and Marc Scott (1998), "Job Instability and Wage Inequality Among Young Men: A Comparison of Two NLS Cohorts." Manuscript.

Bureau of Labor Statistics (1997), "Employee Tenure in the Mid-1990s," news release of 30 January 1997, ftp://146.142.4.23/pub/news.release/tenure.txt.

Diebold, Frank X., David Neumark, and Daniel Polsky (1996), "Comment on Kenneth A. Swinnerton and Howard Wial, 'Is Job Stability Declining in the U.S. Economy?" Industrial and Labor Relations Review, 49, 348-352.

Diebold, Frank X., David Neumark, and Daniel Polsky (1997), "Job Stability in the United States." Journal of Labor Economics 15, 206-233.

Farber, Henry S. (1995), "Are Lifetime Jobs Disappearing? Job Duration in the United States: 1973-1993,” NBER Working Paper No. 5013, February.

Farber, Henry S. (1997). "The Changing Face of Job Loss in the United States, 1981-1995." Manuscript.

Gottschalk, Peter, and Robert Moffitt (1994), "The Growth of Earnings Instability in the U.S. Labor Market," Brookings Papers on Economic Activity, 2:1994, 217-272.

Jaeger, David A. (1997), "Reconciling the Old and New Census Bureau Education Questions: Recommendations for Researchers," Journal of Business and Economic Statistics, 15, 300-309.

Mackinnon, J. G. and Halbert White (1985), "Some Heteroskedasticity-Consistent Covariance Matrix Estimators with Improved Finite Sample Properties," Journal of Econometrics, 29, 305-325.

Marcotte, David (1994) "Declining Job Stability: What We Know and What It Means." Journal of Policy Analysis and Management, 14, 590-598.

Marcotte, David (1996) "Has Job Stability Declined? Evidence from the Panel Study on Income Dynamics," Center for Governmental Studies, Northern Illinois University, unpublished draft.

Monks, J. and S. Pizer (1996) "Trends in Voluntary and Involuntary Job Turnover," Boston College, unpublished draft. 
Neumark, David, Daniel Polsky, and Daniel Hansen (1998) "Has Job Stability Declined Yet? New Evidence for the 1990s." manuscript.

Polsky, Daniel (1996), "Changes in the Consequences of Job Separations in the U.S. Economy," Department of Economics, University of Pennsylvania, unpublished draft.

Rose, Steven (1995), "Declining Job Security and the Professionalization of Opportunity," National Commission for Employment Policy, Research Report 95-4.

Stewart, Jay (1997), "Has Job Mobility Increased? Evidence from the Current Population Survey: 1975-1995," Office of Employment Research and Program Development, Bureau of Labor Statistics, unpublished draft.

Swinnerton, Kenneth A. and Howard Wial (1995), "Is Job Stability Declining the U.S. Economy?" Industrial and Labor Relations Review, 48, 293-394.

Swinnerton, Kenneth A. and Howard Wial (1996), "Is Job Stability Declining in the U.S. Economy? Reply to Diebold, Neumark, and Polsky," Industrial and Labor Relations Review, 48, 352-355.

White, Halbert (1980), "Heteroskedasticity-Consistent Covariance Matrix Estimation and a Direct Test for Heteroskedasticity," Econometrica, 48, 817-838.

Wolter, Kirk (1985), Introduction to Variance Estimation. New York: Springer-Verlag. 
Table 1

Trends in Tenure Probabilities, PSID \& CPS

(Employed Male Household Heads)

\begin{tabular}{|c|c|c|c|c|c|c|c|c|}
\hline \multirow[b]{4}{*}{ Group } & \multicolumn{8}{|c|}{ Coefficient on Linear Trend } \\
\hline & \multicolumn{4}{|c|}{ Tenure $<=1$ Year } & \multicolumn{4}{|c|}{ Tenure $<10$ Years } \\
\hline & \multicolumn{2}{|c|}{ CPS } & \multicolumn{2}{|c|}{ PSID } & \multicolumn{2}{|c|}{ CPS } & \multicolumn{2}{|c|}{ PSID } \\
\hline & $1973-96$ & $1983-96$ & $1976-96$ & $1983-96$ & $1973-96$ & $1983-96$ & $1976-96$ & $1983-96$ \\
\hline Full Sample & $\begin{array}{c}.0015 \\
(.0008)\end{array}$ & $\begin{array}{c}.0020 \\
(.0014)\end{array}$ & $\begin{array}{c}.0027 \\
(.0007)\end{array}$ & $\begin{array}{c}.0011 \\
(.0010)\end{array}$ & $\begin{array}{c}.0001 \\
(.0016)\end{array}$ & $\begin{array}{c}.0040 \\
(.0014)\end{array}$ & $\begin{array}{c}.0046 \\
(.0012)\end{array}$ & $\begin{array}{l}.0079 \\
(.0010)\end{array}$ \\
\hline \multicolumn{9}{|l|}{ Age } \\
\hline $20--29$ years & $\begin{array}{c}.0018 \\
(.0014)\end{array}$ & $\begin{array}{c}.0045 \\
(.0027)\end{array}$ & $\begin{array}{c}.0039 \\
(.0016)\end{array}$ & $\begin{array}{l}-.0002 \\
(.0022)\end{array}$ & & & & \\
\hline $30--39$ years & $\begin{array}{c}.0014 \\
(.0013)\end{array}$ & $\begin{array}{c}.0007 \\
(.0021)\end{array}$ & $\begin{array}{c}.0022 \\
(.0008)\end{array}$ & $\begin{array}{c}.0015 \\
(.0014)\end{array}$ & $\begin{array}{l}-.0002 \\
(.0022)\end{array}$ & $\begin{array}{c}.0030 \\
(.0025)\end{array}$ & $\begin{array}{c}.0029 \\
(.0016)\end{array}$ & $\begin{array}{c}.0070 \\
(.0013)\end{array}$ \\
\hline 40 -- 49 years & $\begin{array}{c}.0015 \\
(.0005)\end{array}$ & $\begin{array}{c}.0014 \\
(.0006)\end{array}$ & $\begin{array}{c}.0027 \\
(.0007)\end{array}$ & $\begin{array}{c}.0028 \\
(.0010)\end{array}$ & $\begin{array}{c}.0004 \\
(.0016)\end{array}$ & $\begin{array}{c}.0057 \\
(.0009)\end{array}$ & $\begin{array}{c}.0064 \\
(.0012)\end{array}$ & $\begin{array}{c}.0109 \\
(.0008)\end{array}$ \\
\hline $50--59$ years & $\begin{array}{c}.0018 \\
(.0003)\end{array}$ & $\begin{array}{c}.0020 \\
(.0008)\end{array}$ & $\begin{array}{c}.0006 \\
(.0007)\end{array}$ & $\begin{array}{l}-.0017 \\
(.0010)\end{array}$ & $\begin{array}{c}.0020 \\
(.0022)\end{array}$ & $\begin{array}{c}.0075 \\
(.0006)\end{array}$ & $\begin{array}{c}.0060 \\
(.0009)\end{array}$ & $\begin{array}{c}.0066 \\
(.0010)\end{array}$ \\
\hline \multicolumn{9}{|l|}{ Education } \\
\hline Less than 12 years & $\begin{array}{c}.0022 \\
(.0008)\end{array}$ & $\begin{array}{c}.0022 \\
(.0007)\end{array}$ & $\begin{array}{c}.0021 \\
(.0008)\end{array}$ & $\begin{array}{l}-.0005 \\
(.0020)\end{array}$ & $\begin{array}{c}.0024 \\
(.0014)\end{array}$ & $\begin{array}{c}.0060 \\
(.0007)\end{array}$ & $\begin{array}{c}.0050 \\
(.0013)\end{array}$ & $\begin{array}{c}.0035 \\
(.0031)\end{array}$ \\
\hline 12 years & $\begin{array}{c}.0015 \\
(.0005)\end{array}$ & $\begin{array}{c}.0022 \\
(.0003)\end{array}$ & $\begin{array}{c}.0031 \\
(.0004)\end{array}$ & $\begin{array}{c}.0027 \\
(.0007)\end{array}$ & $\begin{array}{c}.0005 \\
(.0017)\end{array}$ & $\begin{array}{c}.0046 \\
(.0005)\end{array}$ & $\begin{array}{c}.0038 \\
(.0022)\end{array}$ & $\begin{array}{c}.0091 \\
(.0024)\end{array}$ \\
\hline 13 -- 15 years & $\begin{array}{c}.0009 \\
(.0013)\end{array}$ & $\begin{array}{c}.0018 \\
(.0029)\end{array}$ & $\begin{array}{c}.0029 \\
(.0012)\end{array}$ & $\begin{array}{c}.0008 \\
(.0022)\end{array}$ & $\begin{array}{l}-.0004 \\
(.0017)\end{array}$ & $\begin{array}{c}.0031 \\
(.0028)\end{array}$ & $\begin{array}{c}.0072 \\
(.0010)\end{array}$ & $\begin{array}{l}.0111 \\
(.0009)\end{array}$ \\
\hline 16 or more years & $\begin{array}{c}.0009 \\
(.0006)\end{array}$ & $\begin{array}{c}.0011 \\
(.0012)\end{array}$ & $\begin{array}{c}.0019 \\
(.0009)\end{array}$ & $\begin{array}{l}-.0000 \\
(.0009)\end{array}$ & $\begin{array}{l}-.0006 \\
(.0025)\end{array}$ & $\begin{array}{c}.0045 \\
(.0024)\end{array}$ & $\begin{array}{c}.0057 \\
(.0014)\end{array}$ & $\begin{array}{c}.0095 \\
(.0015)\end{array}$ \\
\hline \multicolumn{9}{|l|}{ Race } \\
\hline White & $\begin{array}{c}.0014 \\
(.0009)\end{array}$ & $\begin{array}{c}.0019 \\
(.0017)\end{array}$ & $\begin{array}{c}.0023 \\
(.0007)\end{array}$ & $\begin{array}{c}.0006 \\
(.0011)\end{array}$ & $\begin{array}{c}.0001 \\
(.0017)\end{array}$ & $\begin{array}{c}.0039 \\
(.0015)\end{array}$ & $\begin{array}{c}.0045 \\
(.0011)\end{array}$ & $\begin{array}{c}.0072 \\
(.0009)\end{array}$ \\
\hline Black & $\begin{array}{c}.0022 \\
(.0006)\end{array}$ & $\begin{array}{c}.0035 \\
(.0031)\end{array}$ & $\begin{array}{c}.0061 \\
(.0010)\end{array}$ & $\begin{array}{c}.0048 \\
(.0014)\end{array}$ & $\begin{array}{l}-.0000 \\
(.0012)\end{array}$ & $\begin{array}{c}.0041 \\
(.0008)\end{array}$ & $\begin{array}{c}.0036 \\
(.0000)\end{array}$ & $\begin{array}{l}.0146 \\
(.0040)\end{array}$ \\
\hline
\end{tabular}

NOTE: Standard errors in parentheses. Tenure $<=1$ year samples include all individuals age 20-59, tenure $<10$ years samples include all individuals age 30-59. First stage logit regressions include control variables for age, age squared, education group and race group (where appropriate). Second stage is regression of adjusted year-specific predicted probabilities on time trend.

Predicted probabilites are calculated at the mean value of the control variables. Standard errors are estimated using the jackknife. 
Figure 1

Alternative "Job" Tenure Series--PSID

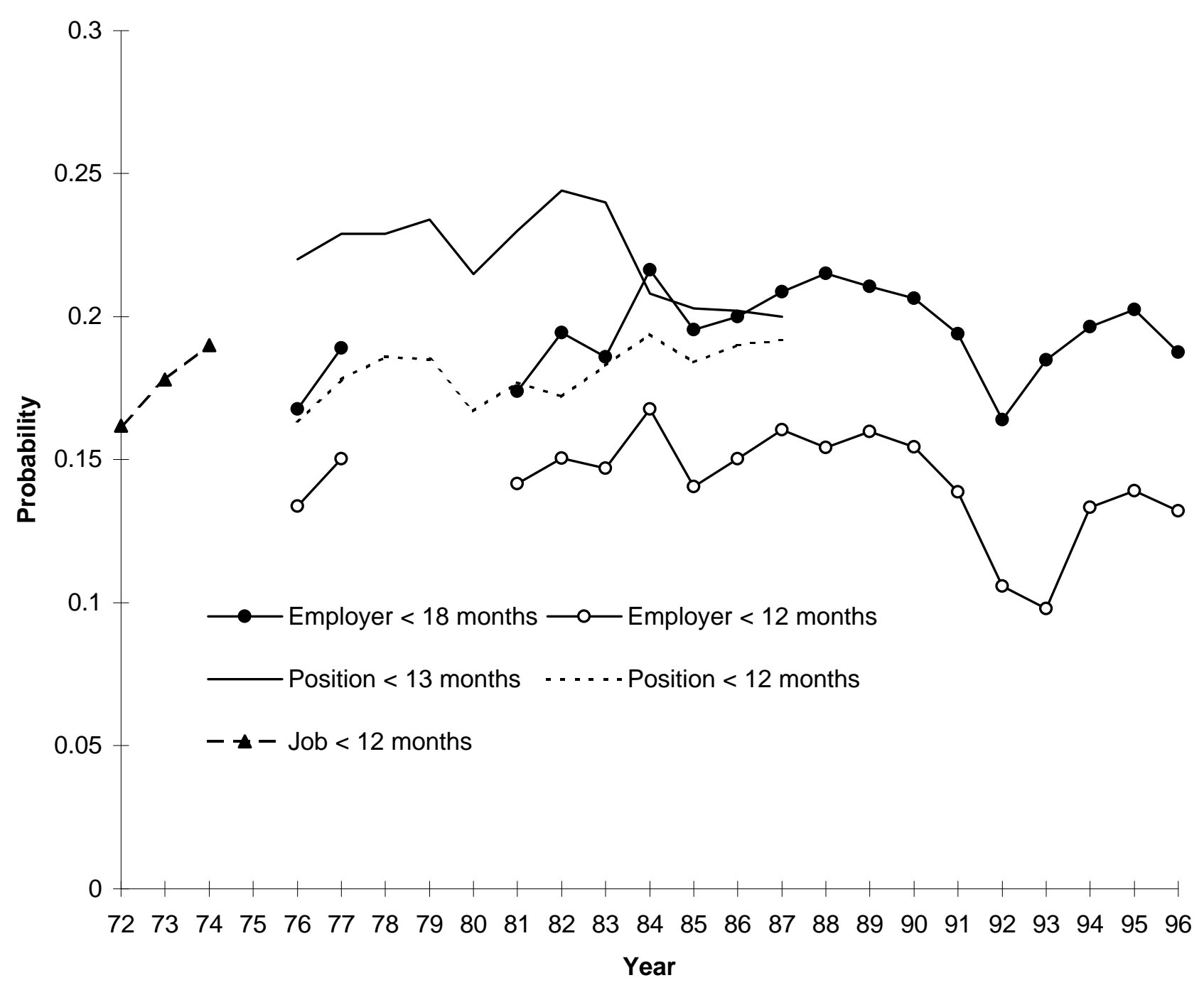


Figure 2b

Probability of Tenure $<=1$-- PSID \& CPS

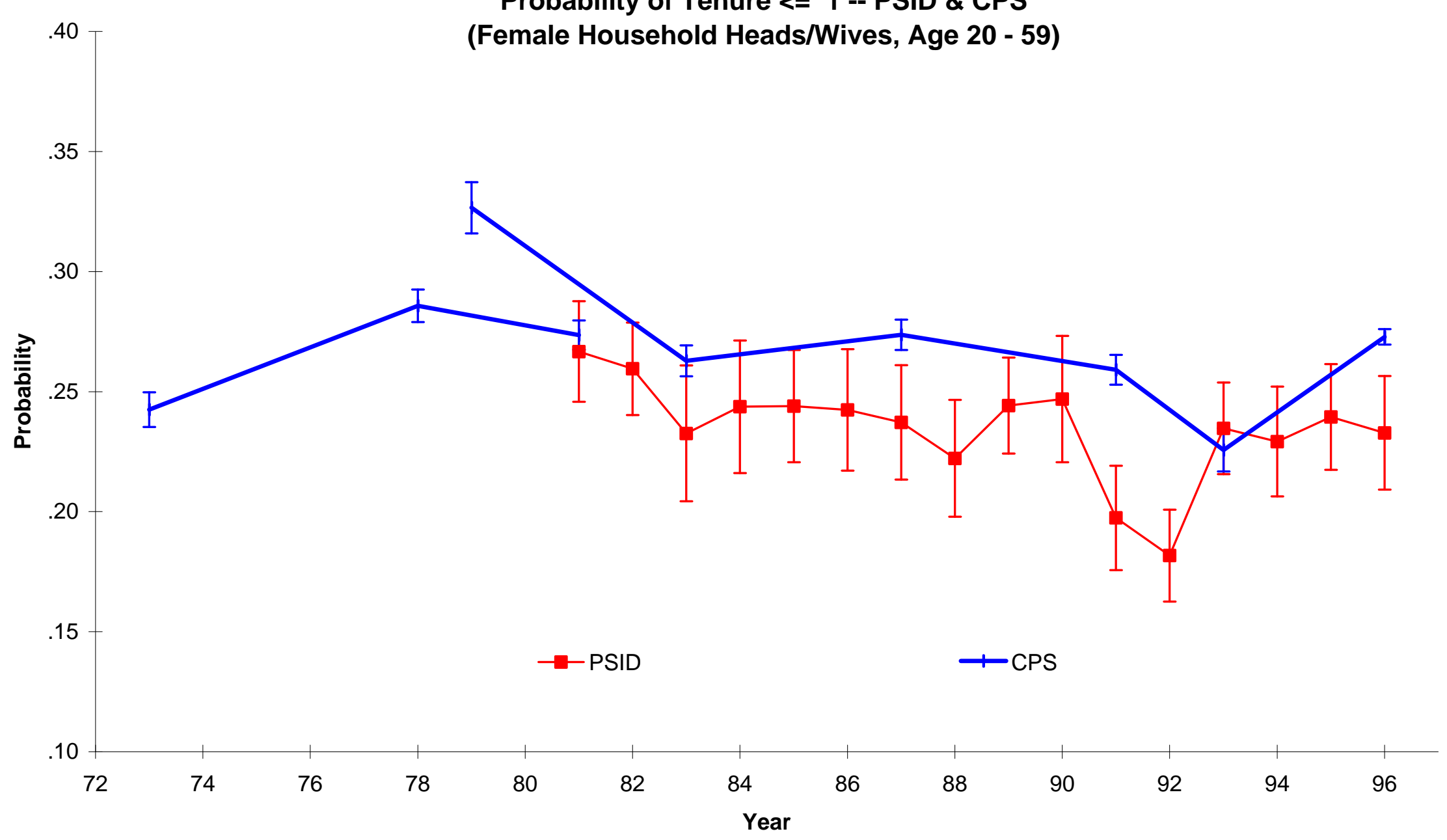




\section{Figure 3a}

Fraction with Low Tenure by Age Groups for Male Household Heads-- PSID and CPS

( $2 \times$ standard error bars)

\section{Panel A: Ages 20-29}

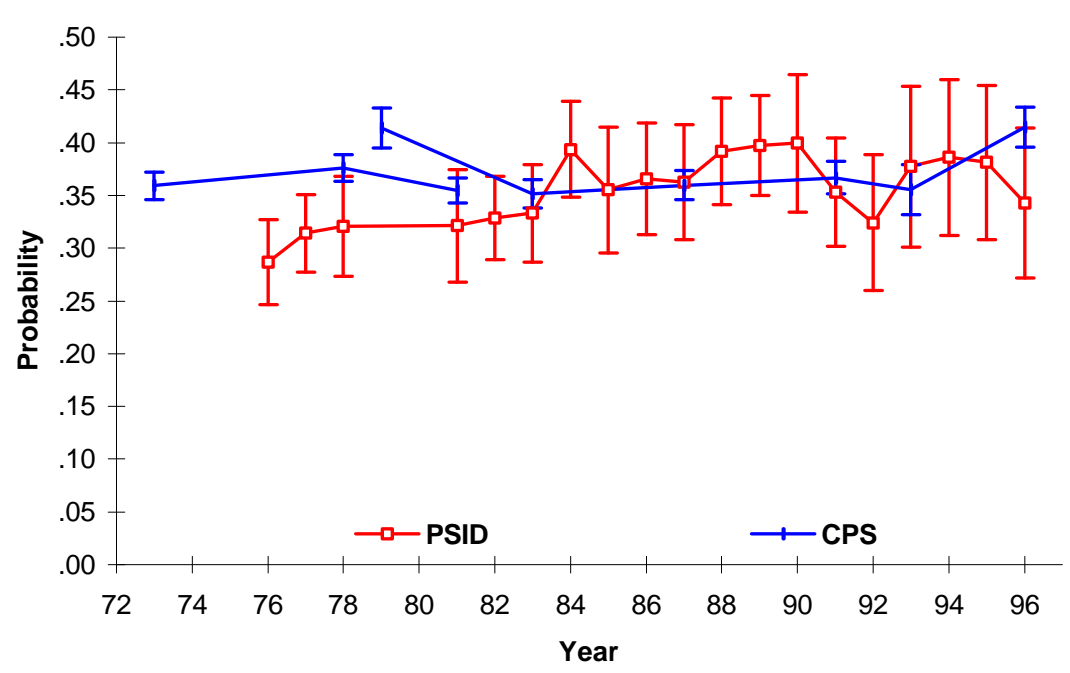

Panel C: Ages 40-49

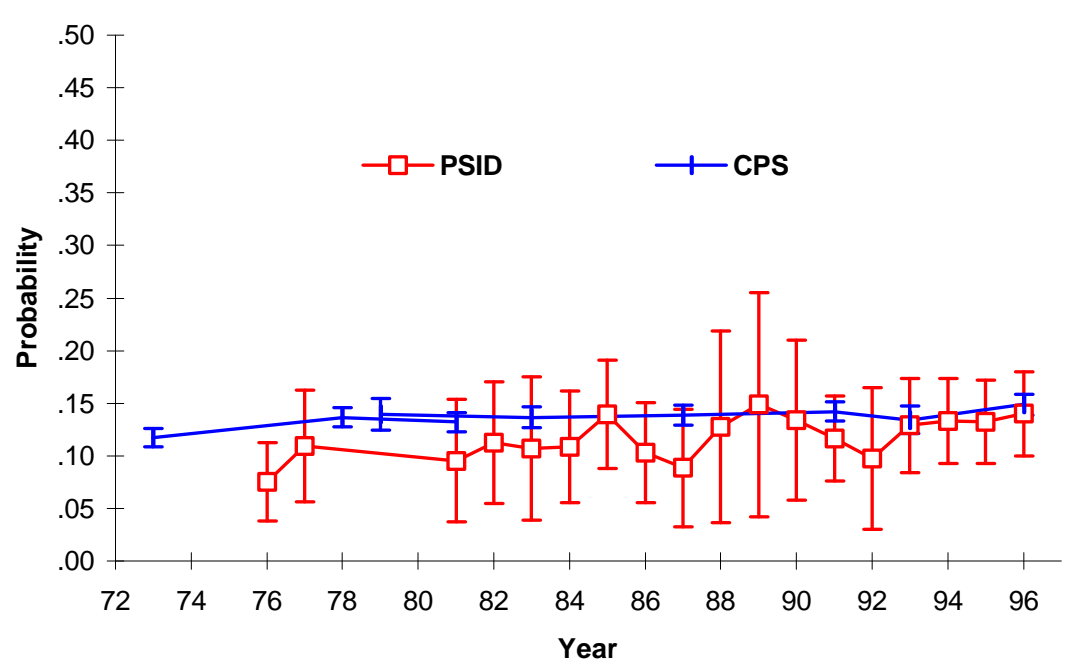

Panel B: Ages 30-39

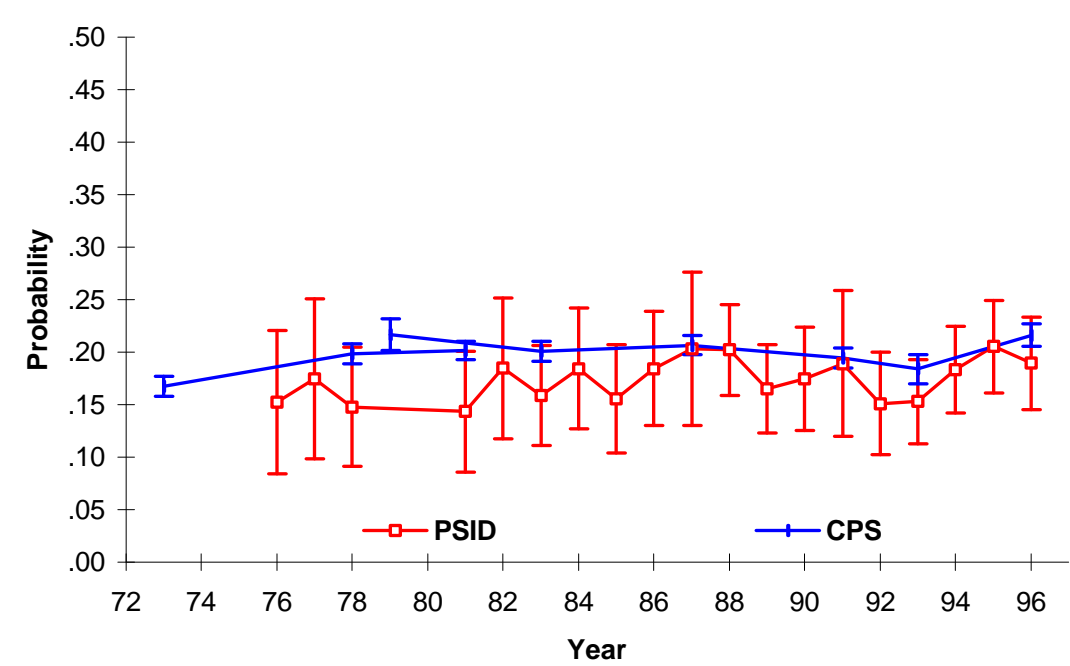

Panel D: Ages 50-59

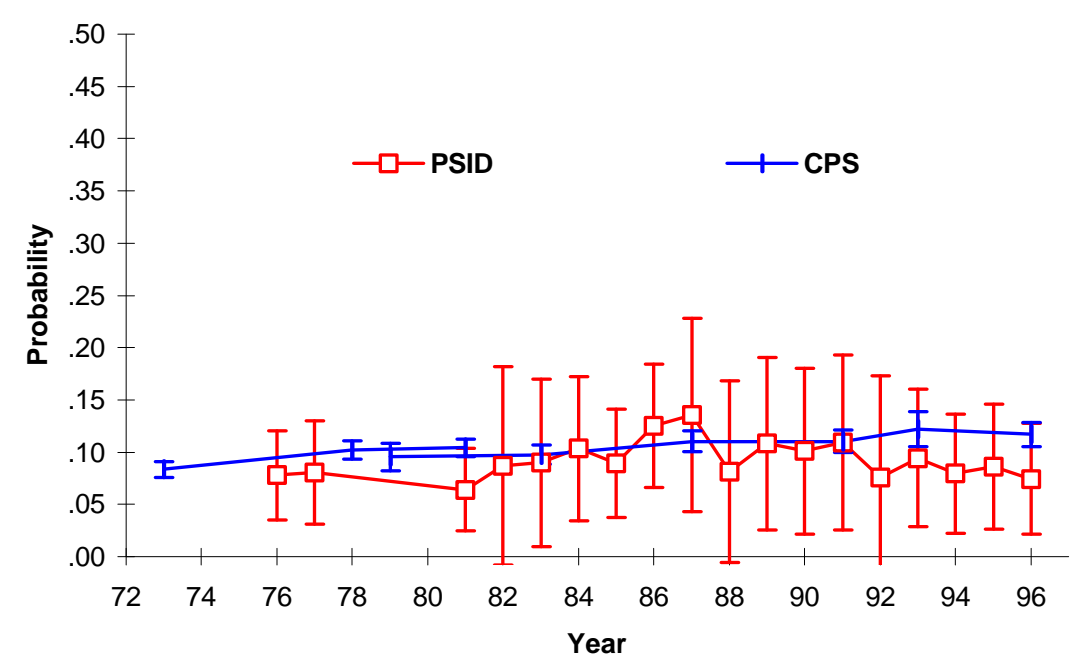

SOURCE: CPS: Tenure and employee benefits supplements; PSID: weighted full sample. 


\section{Figure 3b}

Probability of Tenure <= 1 Year by Age Groups for Female Heads \& Wives -- PSID and CPS

( 2 x standard error bars)
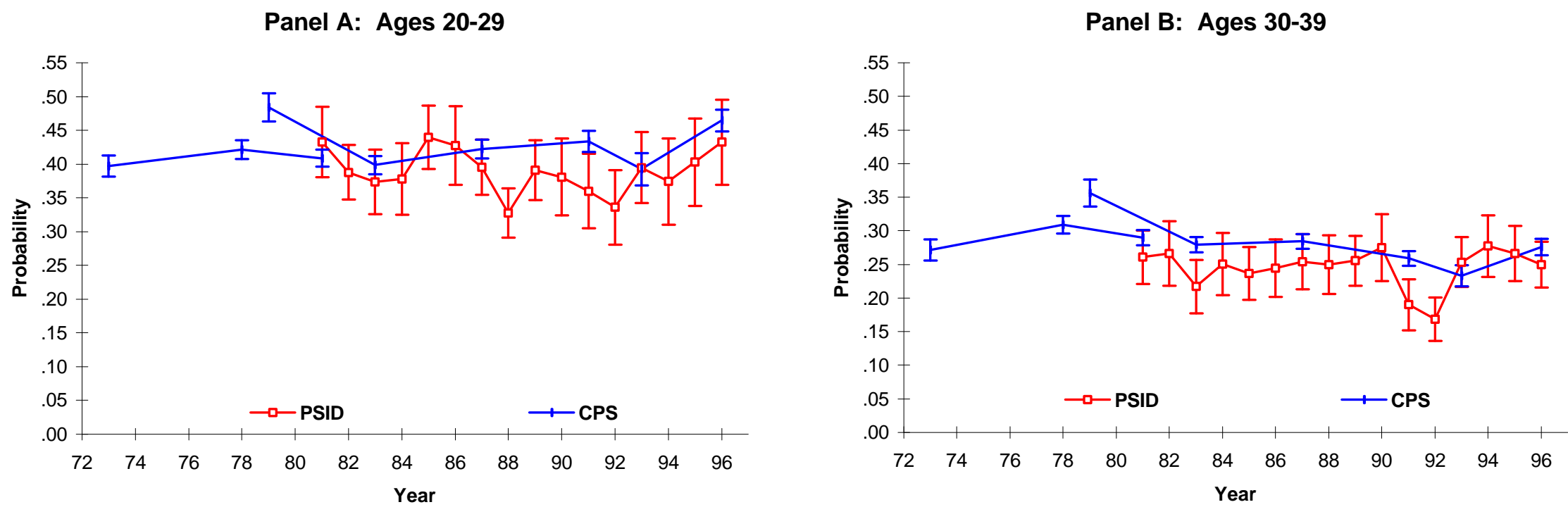

Panel C: Ages 40-49

Panel D: Ages 50-59
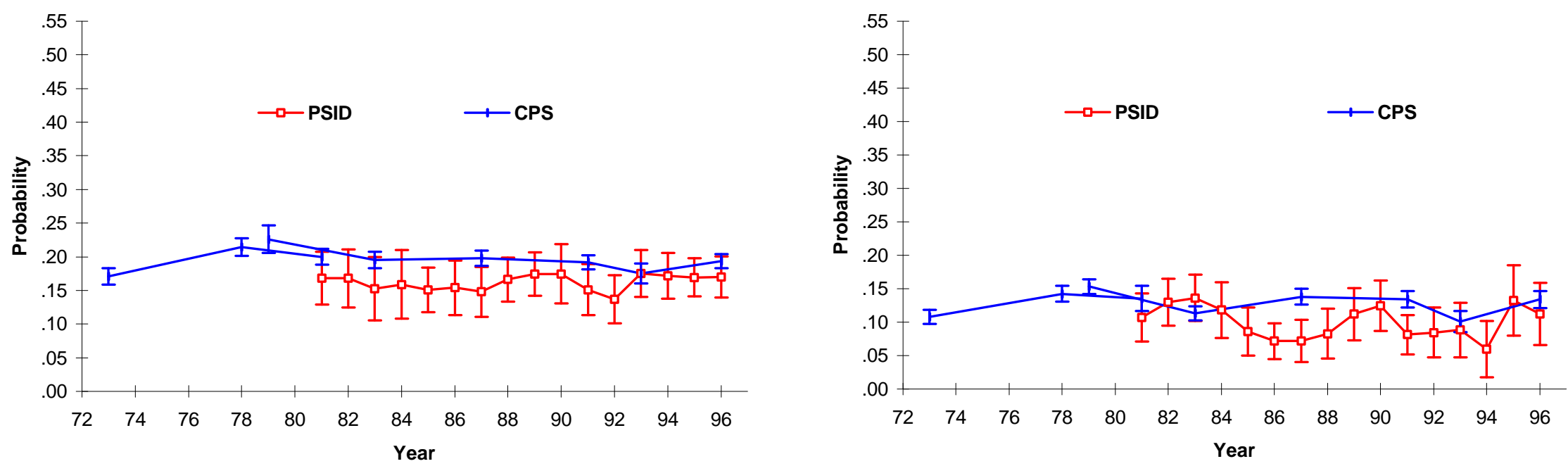

SOURCE: CPS: Tenure, employee benefits, and displaced workers supplements; PSID: weighted full sample. 


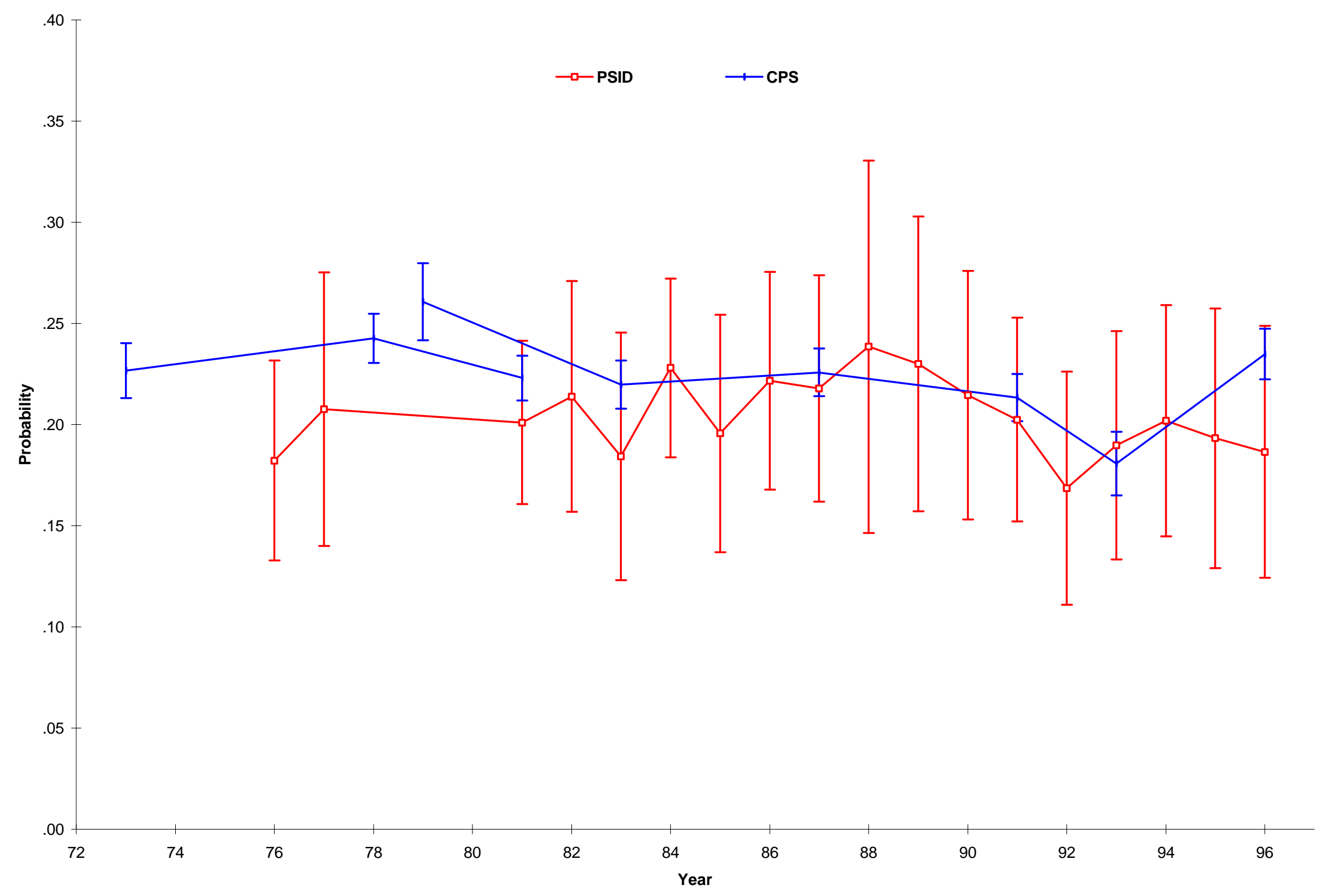




\section{Figure 4b}

Probability of Tenure <= 1 Year by Education Groups for Female Heads / Wives -- PSID and CPS

( $2 \times$ standard error bars)

Panel A: Less than 12 years

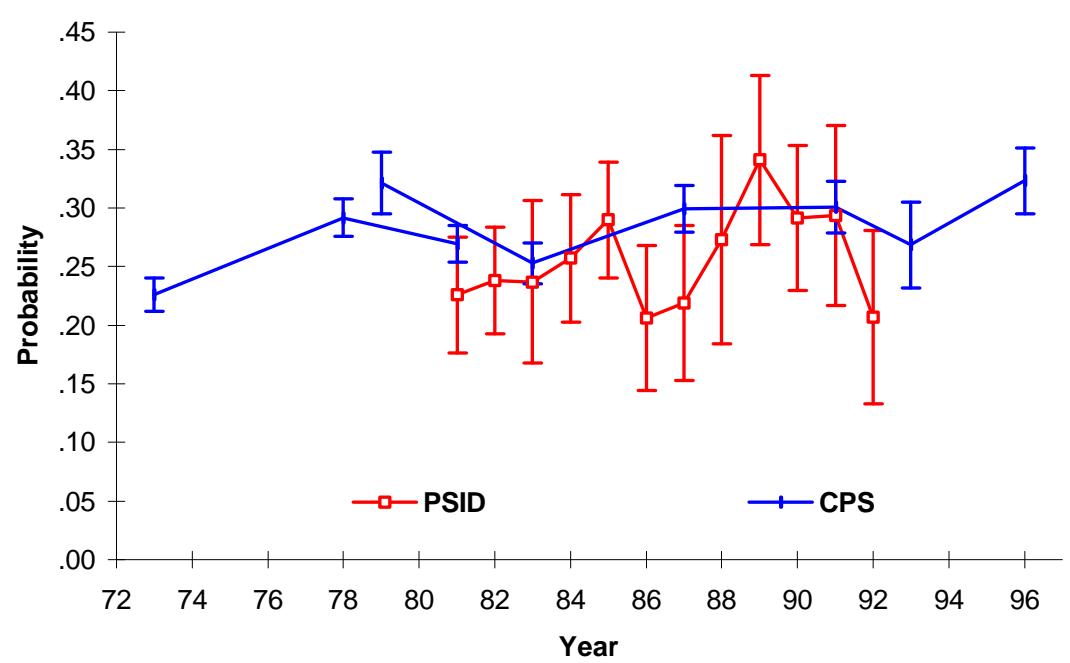

Panel C: $13-15$ years

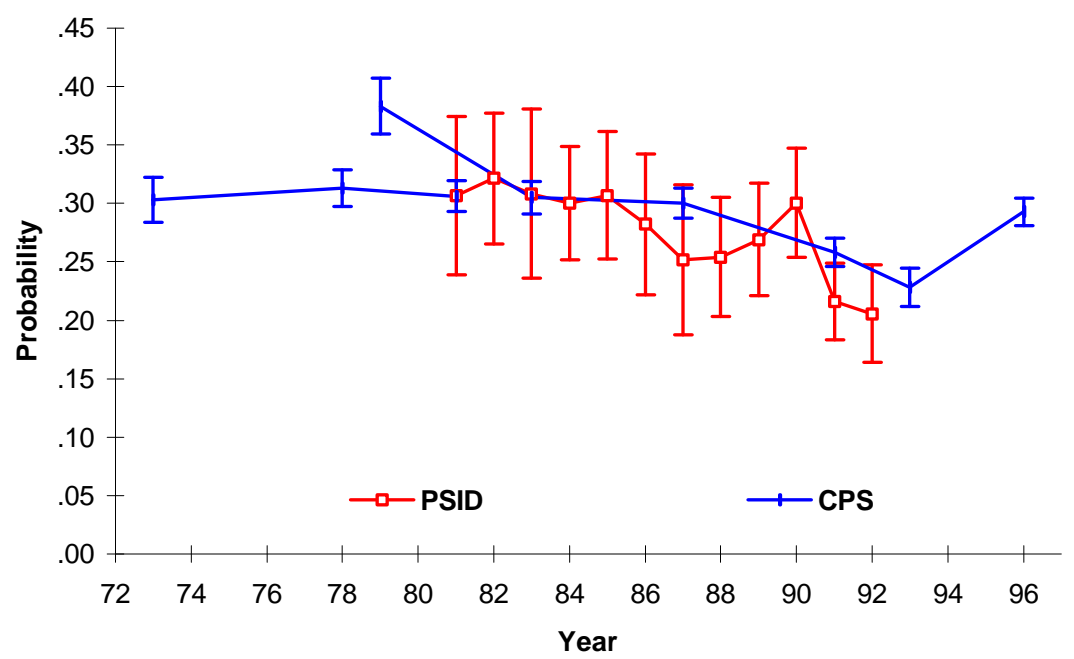

Panel B: 12 years

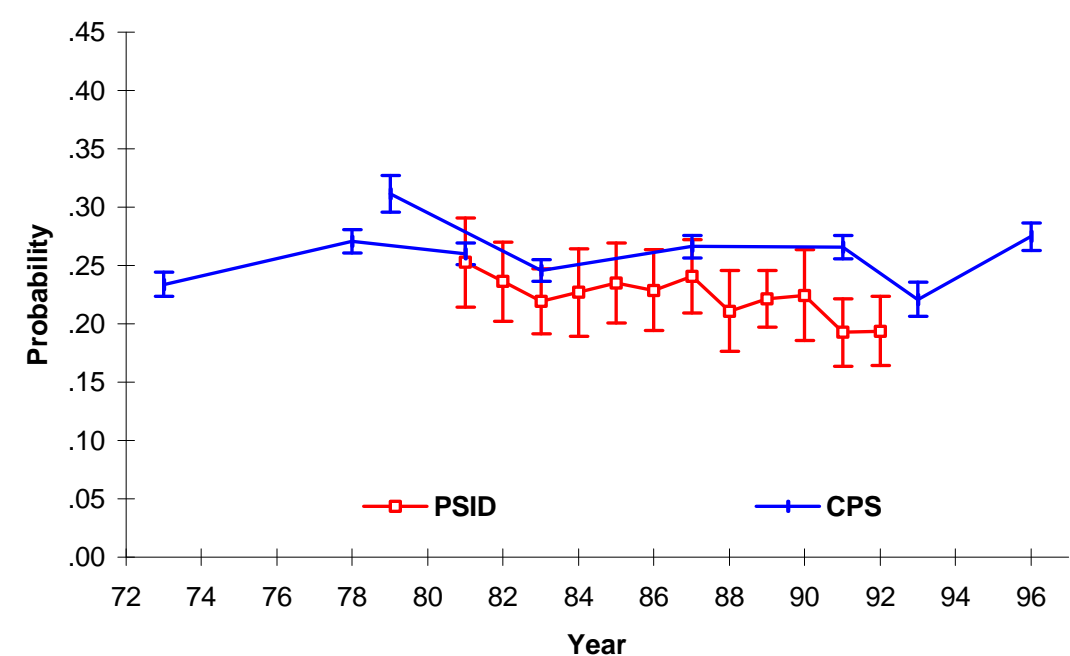

Panel D: 16 years

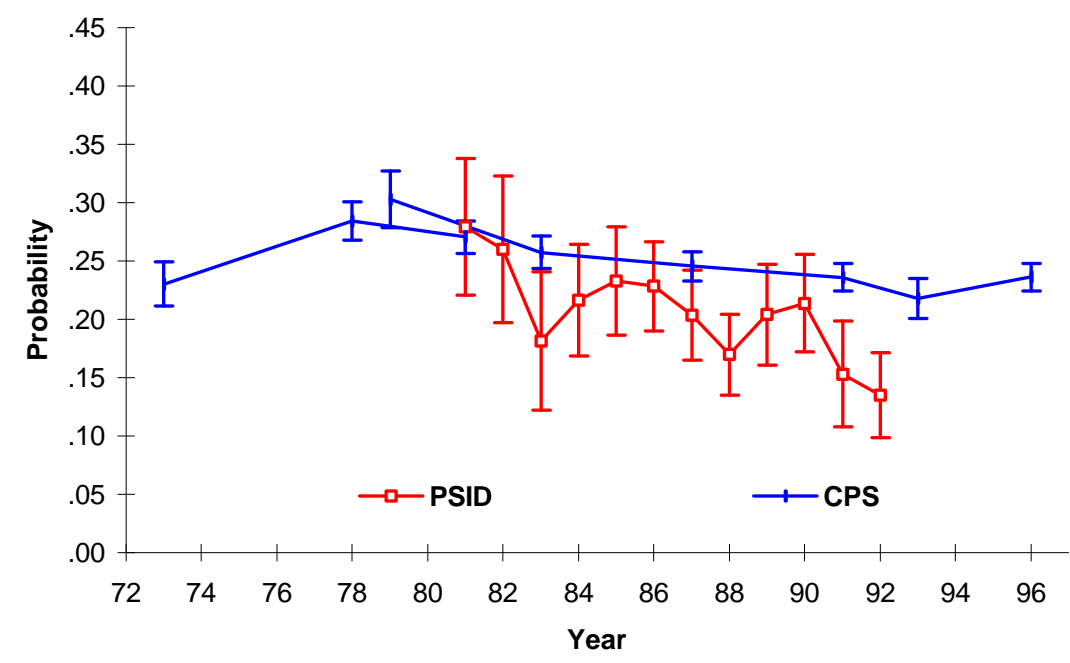

SOURCE: CPS: Tenure and employee benefits supplements; PSID: weighted full sample. NOTE: Sample is female household heads and wives, aged 20-59 at the time of the survey. 
Figure 5

Probability of Tenure $<10$ Years by Age and Sex-- PSID and CPS

( $2 \times$ standard error bars)

Panel A1: Men, Ages 30-39

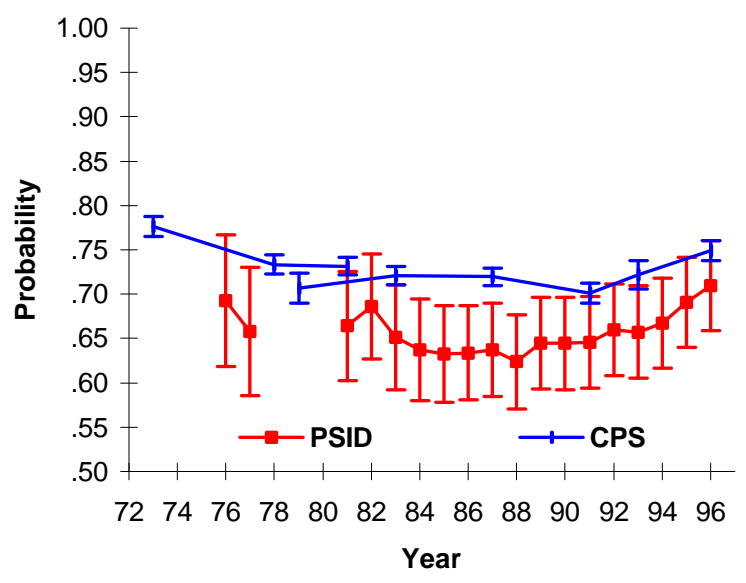

Panel B1: Men, Ages 40-49

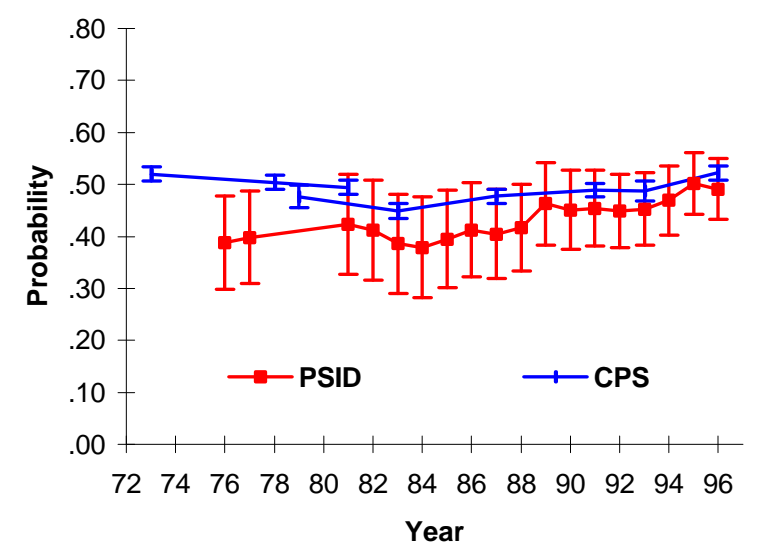

Panel C1: Men, Ages 50-59

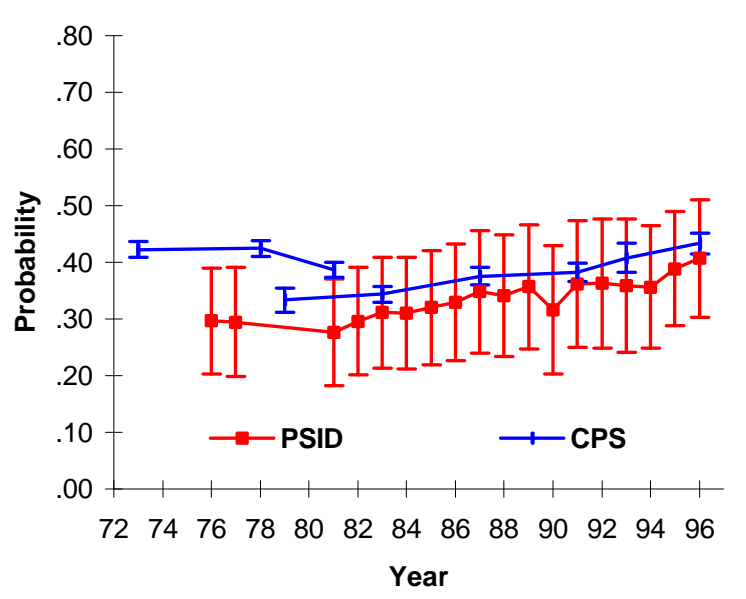

Panel A2: Women, Ages 30-39

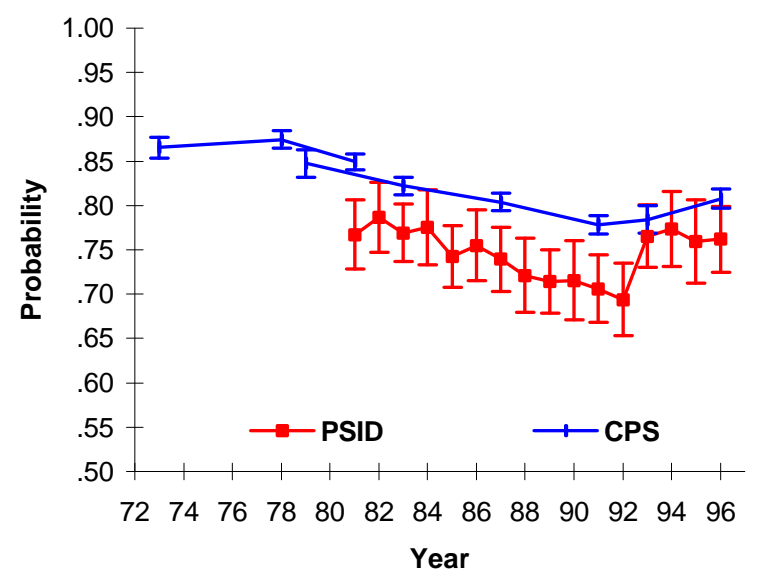

Panel B2: Women, Ages 40-49

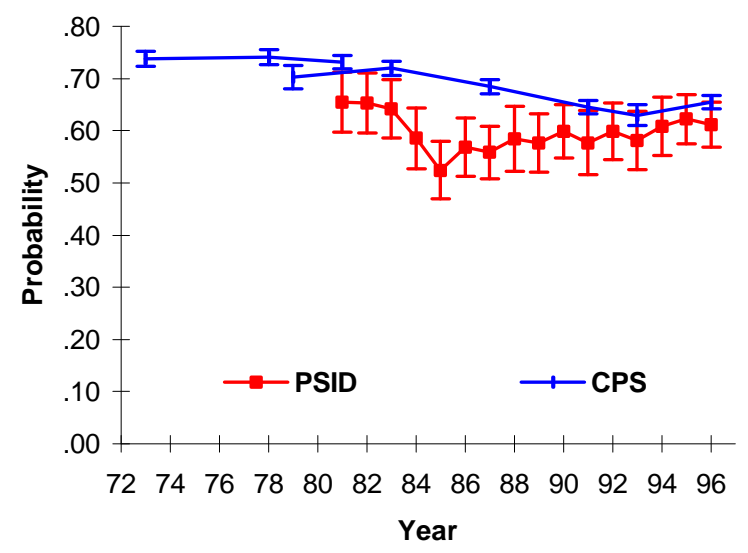

Panel C2: Women, Ages 50-59

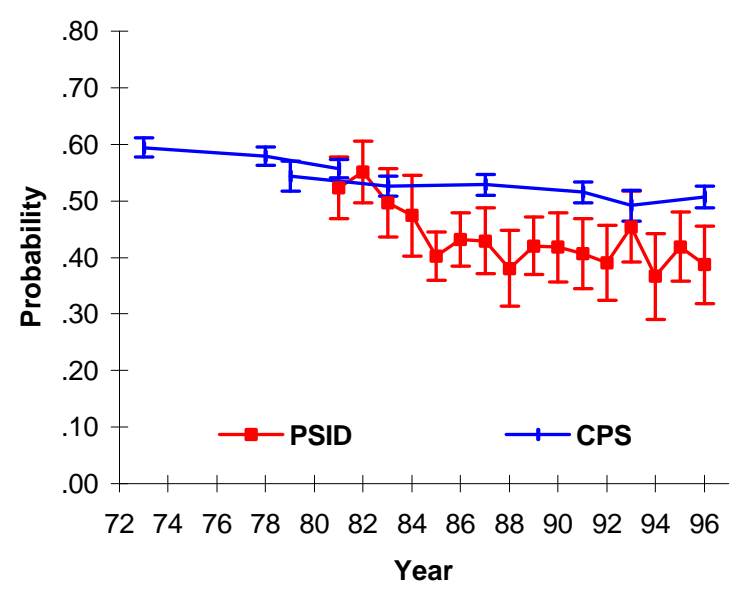

SOURCE: CPS: Tenure and employee benefits supplements; PSID: weighted full sample. NOTE: Vertical scale is different in each panel. 